\title{
COST ESTIMATION METHODS OF MACHINE ELEMENTS AT THE DESIGN STAGE IN UNIT AND SMALL LOT PRODUCTION CONDITIONS
}

\author{
Dorota WIĘCEK, Dariusz WIĘCEK \\ University of Bielsko-Biala \\ Ivan KURIC \\ University of Zilina
}

\begin{abstract}
:
On the stage of product design there is a problem concerning production cost estimation in the moment when elements are not yet definitely designed. Depending on the amount of the available information, more or less precise cost estimation methods are applied, i.e.: variant methods, generation methods, hybrid methods. The proposed method of cost estimation is based on a formalized description of information related to construction, manufacturing and organizational characteristics concerning the designed element, the automation method of technological processes design using methods of group technology and a model of determining production costs of machine elements based on Activity Based Costing.
\end{abstract}

Key words: activity based costing, production cost estimation, cost drivers

\section{INTRODUCTION}

The situation on the market makes companies constantly monitor and look for savings in total production costs, while maintaining appropriate quality of the manufactured products. The best results in reducing costs can be achieved in the initial phases of the product life cycle, at the design and development stages of production processes, i.e. when it affects the largest number of factors determining the final manufacturing cost, in which the concept and product structure are created, and the material, the technological process and parameters of the manufacturing process are selected [1, 2, 3]. A prompt and relatively accurate cost estimation allows to avoid excessive spending during the production launch of these products. In the design process, we have an influence on $70-80 \%$ of the costs of subsequent processes, i.e. supply, planning, production and sales, which depend on the amount of information related to the design, manufacture and production organization of the designed elements - Figure 1 [4]. The more information we possess about the designed elements, the lower share in product cost belongs to undetermined product costs. The more advanced the manufacturing process is, the smaller the chances to decrease prime costs due to large expenditure on process modification.

Selecting the proper cost estimation method according to the production type may significantly influence the accuracy and reliability of the performed calculations. Applying
Activity-based Costing, including cost drivers, allows to considerably reduce costs on the stage of production processes design, which actively influences cost planning in the future. This allows for changing the approach from delivering historical data about operational effectiveness, into managing costs of efficiency of future periods $[5,6]$.

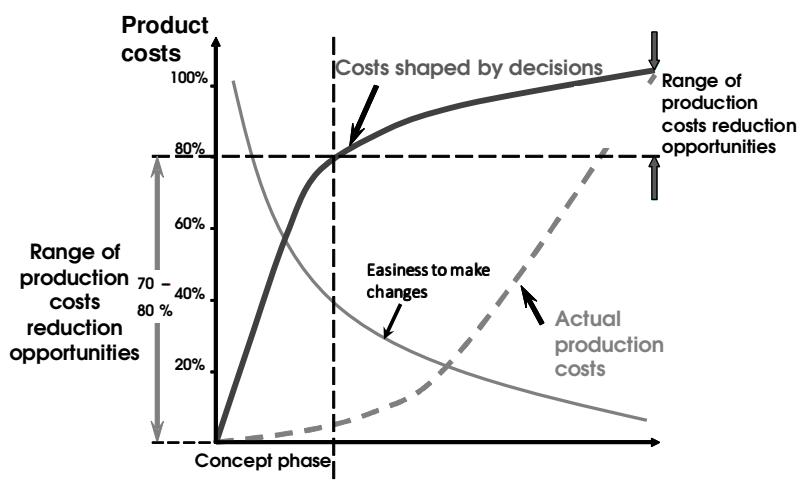

Fig. 1 The paradox of cost estimation Source: Developed on the basis of [4].

The aim of the research is to develop methods of cost estimation of the designed products on the stage of constructional production preparation, which would be based on proper selection of cost drivers related to actual rates from activity based costing, in order to optimally and relatively quickly estimate the cost of a designed element, depending on constructional information. Solving the above problem 
in enterprises with unit and small series production requires:

- $\quad$ assuming proper description of the designed elements basing on the elementary object method, which takes into consideration constructional, manufacturing and organizational features

- determining activity costs for an exemplary production system, with accuracy corresponding to the description of features of the designed elements,

- compiling a set of cost drivers, on the basis of the assumed cost estimation method

- determining the level of cost drivers basing on the values of the assumed description of the designed elements features

- designing a cost calculation model which would consider the available sets of cost drivers and actual activity rates.

\section{METHODS OF COST ESTIMATION}

The two available approaches aiming at achieving an optimal level of production costs, denoted as DFc and target costing, are presented in Table 1 [4].

Table 1 Concepts of reducing costs of a designed element uses all organizational and technical possibilities in order to re-

$\begin{array}{lll}\text { Design for cost } & \begin{array}{l}\text { nical possibilities in order to re- } \\ \text { duce total production costs of the } \\ \text { designed product }\end{array} \\ \begin{array}{ll}\text { (DFc) } & \text { aims at reaching satisfactory pa- } \\ \text { rameters of a designed product } \\ \text { within the assumed target cost }\end{array} \\ \begin{array}{ll}\text { Design to cost } \\ \text { (Target costing) }\end{array} & \begin{array}{l}\text { within } \\ \end{array}\end{array}$

These concepts require applying appropriate methods of calculating costs allowing to determine total production costs of the designed products in an early stage of product life cycle, using the information about the product available on this stage. The methods are called cost estimation methods, as they operate on an incomplete set of data about the designed product, needed to determine a possible level of total production costs. This is a process of approximate production costs determination, which is based on information generated at each completed stage of the cycle before all phases of the production cycle are realized [7]. Literature contains more or less precise methods for estimating costs, which depend on the amount of information on the designed product. Table 2 presents the division of the methods into basic groups, together with their brief description.

The mentioned methods of cost estimation of machine elements are characterized by limited accuracy of the obtained results. The methods described in literature [5] can be used if all characteristic features of a product are known, and the designed manufacturing process is similar to the previously produced items, which brings about some restrictions to applying such methods from the point of view of accuracy of the obtained results [8]. The methods relate to various stages of the production cycle, so a different method proves more effective in a given stage.
Table 2

Methods of cost estimation

\begin{tabular}{lc}
\hline Groups & Characteristics \\
\hline Intuitive & They are based on knowledge and experience
\end{tabular}
methods of an expert, who can estimate production (by experi- cost of the designed element on the basis of ence) the possessed information. However, the results are uncertain and often inaccurate, as they depend on subjective evaluation. On the other hand, these methods of cost estimation are very cheap.

Analogous The methods allow to determine the costs of (variant) the designed products based on similarity methods with other previously produced products in a given production system using classification systems. They are applied parallelly with the group technology methods used for designing production processes.

Analytical They use the known (previously incurred, his(genera- torical) costs of elementary tasks, decompostional) meth- ing the adopted production method for deods termining costs of the designed product. The obtained results are characterized by high accuracy, but these methods are very expensive compared to others.

Statistical They aim at bringing costs to the function of and para- several important parameters, which can be metric meth- easily determined in the initial stages of prodods Source: [4]. uct design.

Referring to the choice of one of the methods resulted in limited application of the above-mentioned solutions in terms of accuracy of the results obtained in different phases of the production process. In order to determine correct manufacturing costs, apart from the information related to the values of geometric and technological parameters of the product and process being designed, preliminary information on production organization is also required $[9,10]$. The cost estimation systems are based on fixed, often outdated cost data, which, in a situation of constantly altering structure of the encumbered expenses, causes that the estimated costs considerably differ from the actual costs borne on their production. These methods usually make use of traditional cost accounting, and, in case of activity based costing, they are limited to only processing activities, without taking into account other costs, which may be later added in form of surcharges [9]. The problem of cost estimation on the stage of product design occurs when the elements are not definitely designed, or considerably differ from the previously manufactured products, which is characteristic and frequent in case of unit or small lot production $[9,11]$.

\section{THE ASSUMPTIONS OF THE PROPOSED COST ESTIMA- TION METHOD OF MACHINE ELEMENTS}

The proposed model of conduct, presented in Figure 2, aims at accurate estimation of total production costs on the stage of designing and processing new products in unit and small-series production, depending on the available information about the designed product. This system connects the formalized description of the information 
(features) of the designed element and a model of production costs determination basing on the activity based costing method, and locates the proposed method among hybrid methods of cost estimation.

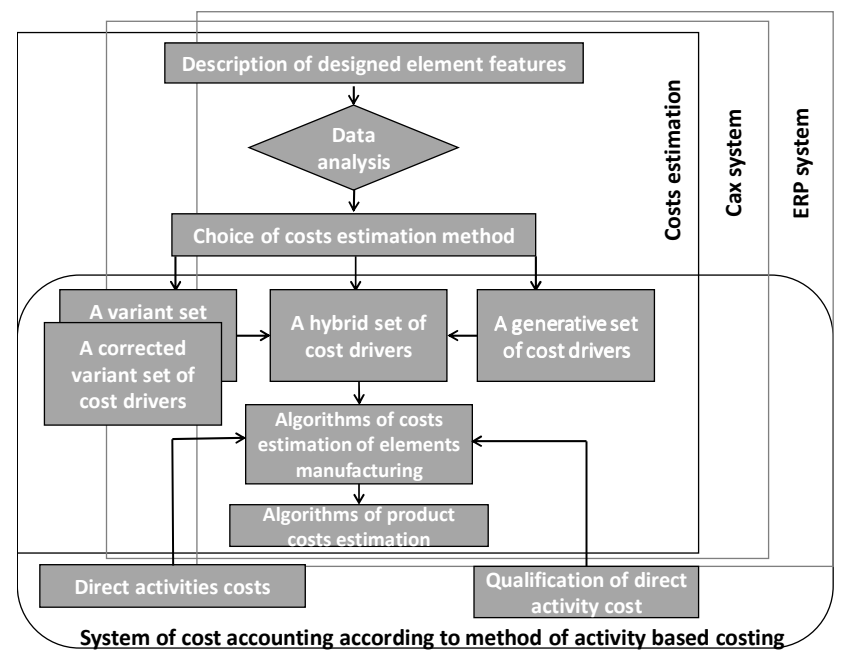

Fig. 2 A model of cost estimation for machine elements

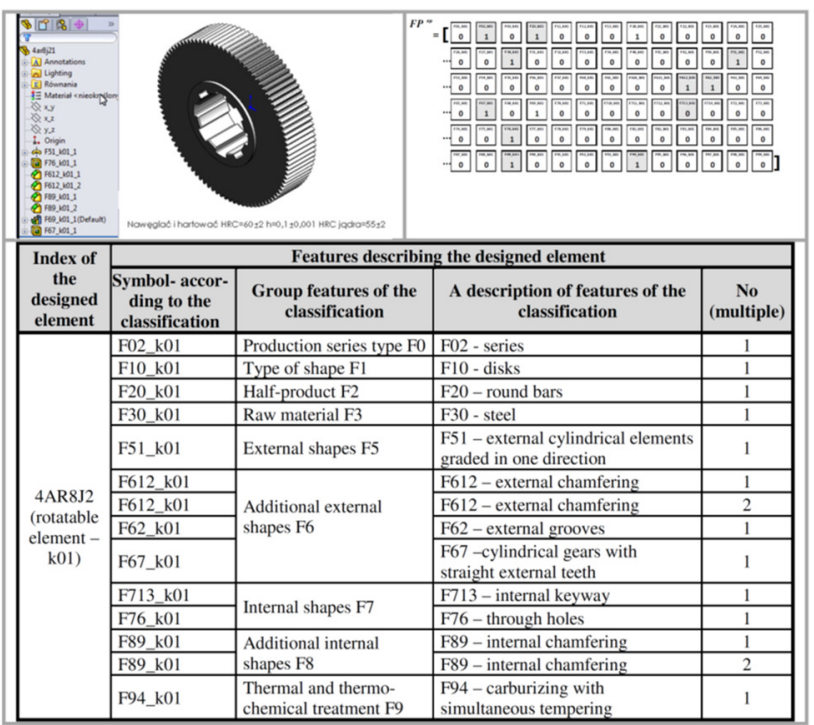

Fig. 3 The geometrical form and formalized set of features of the designed element, together with description of symbols included in the FP vector- an example

The suggested method of cost estimation applies the principle of identifying elements which allows for finding the previously designed manufacturing processes of similar machine elements. This can be performed by using a system describing features of the designed item - Figure 3 which considers [9]:

- constructional features, which, in turn, consist of geometrical features, like shape type, external shapes, additional external shapes, etc., and materials features, e.g. semi-product, raw material, thermal treatment, etc.

- organizational features, e.g. serial character of production, production capacity, etc.

- features related to manufacturing, e.g. variant of the manufacturing process structure, the applied workshop aids, etc.

An important element of the system describing the designed elements are structural elementary objects, which directly constitute the constructional form of the designed element - Figure 4. Each elementary object is associated with one structural feature that describes it [11].

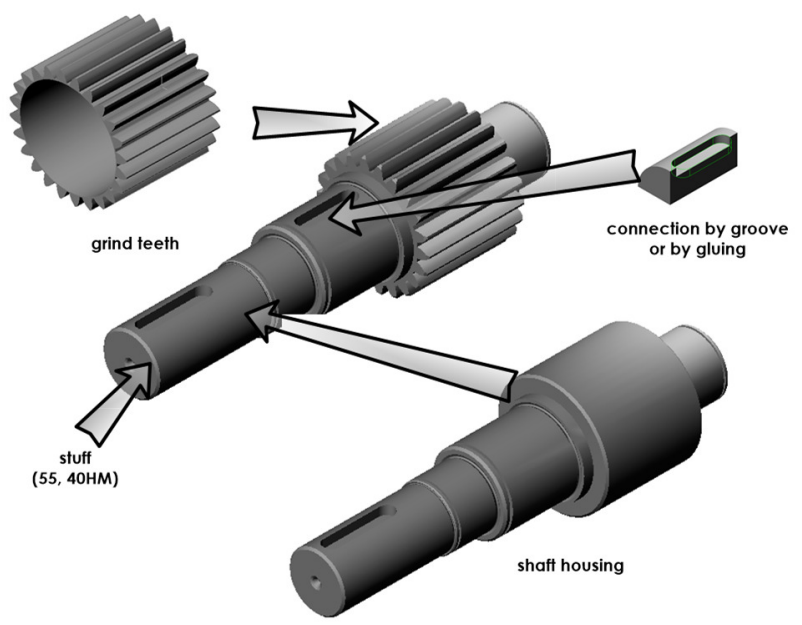

Fig. 4 Examples of elementary objects

On the basis of the similarity of the above mentioned features related to the new element and an already produced one, a manufacturing process is searched for. In other words, basing on a parametrical description of the designed element necessary for searching the existing base of manufacturing processes, the process course for a previously designed element is selected, which is the closest to the new element in terms of structural, manufacturing and organizational characteristics [9].

A vital element of this system is to appropriately apply activity based costing, considering as many accounting bases as there are separated kinds of activities [5]. However, it is important to underline that activity costs should be property settled on each level of product structure (sets, sub-sets, elements, or elementary objects), and the account should show the differences in costs for different design concepts, with detail up to particular technological operations. The next step involves establishing the value of cost components constituting the structure of the production costs. The basic components in this methodology are costs of direct activities, which are cost drivers assigned to the produced elements, sets, products, etc.

According to the information generated on different stages of production process design, aided by the CAx system (computer aided ...), or the information stored in databases $[12,13]$, the code of conduct depends on the possibility of determining a set of cost drivers.

Therefore, it is vital to establish such manufacturing process parameters for particular product structure levels (elementary objects, elements, sub-sets, sets and the whole product), which unambiguously determine the values of the variables specifying cost components together with the manner of their estimation. These costs are determined on the basis of cost drivers values - Table 3 , which, depending on the available information about the designed element, are settled according to various algorithms related to:

- determination of a variant set of cost drivers,

- determination of a corrected variant set of cost drivers, 
- determination of a generative set of cost drivers,

- determination of a hybrid set of cost drivers.

Basing on current rates of activity costs determined in a given accounting period, estimated costs of the designed elements are calculated, which, depending on the method of generating the value of a cost drivers set, are called variant costs, corrected variant costs, generative costs and hybrid costs.

Table 3 Examples of cost drivers

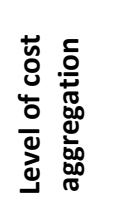

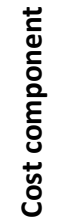

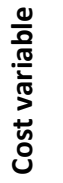

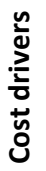

\begin{tabular}{|c|c|c|c|}
\hline $\begin{array}{l}\text { element } \\
\text { level }\end{array}$ & $\begin{array}{l}\text { cost of di- } \\
\text { rect mate- } \\
\text { rials }\end{array}$ & $\begin{array}{l}\text { material unit } \\
\text { price }\end{array}$ & $\begin{array}{l}\text { dimension of starting } \\
\text { material - } x \\
\text { dimension of starting } \\
\text { material - } y \\
\text { dimension of starting } \\
\text { material - } z \\
\text { standard number of } \\
\text { semi-product } \\
\text { material density } \\
\text { raw material } \\
\text { standard number of } \\
\text { semi-product } \\
\text { dimension of starting } \\
\text { material - } x \\
\text { dimension of starting } \\
\text { material - } y \\
\text { dimension of starting } \\
\text { material - } z\end{array}$ \\
\hline $\begin{array}{l}\text { element } \\
\text { level }\end{array}$ & $\begin{array}{l}\text { activity } \\
\text { costs of } \\
\text { processing } \\
\text { the } n \text {-th } \\
\text { technologi- } \\
\text { cal opera- }\end{array}$ & $\begin{array}{l}\text { number of } \\
\text { units } \\
\text { of activity } \\
\text { measure }\end{array}$ & $\begin{array}{l}\text { auxiliary time related } \\
\text { to technological oper- } \\
\text { ation } \\
\text { set-up and break- } \\
\text { down time } \\
\text { size of a production } \\
\text { batch }\end{array}$ \\
\hline & tion & $\begin{array}{l}\text { rate of ac- } \\
\text { tivity }\end{array}$ & production position \\
\hline $\begin{array}{l}\text { element } \\
\text { level }\end{array}$ & $\begin{array}{l}\text { activity } \\
\text { costs of the } \\
\text { procure- } \\
\text { ment pro- } \\
\text { cess }\end{array}$ & $\begin{array}{l}\text { number of } \\
\text { units } \\
\text { of activity } \\
\text { measure } \\
\text { rate of ac- } \\
\text { tivity } \\
\text { number of }\end{array}$ & $\begin{array}{l}\text { standard number of } \\
\text { semi-product } \\
\text { standard materials } \\
\text { usage } \\
\text { standard number of } \\
\text { semi-product }\end{array}$ \\
\hline element & $\begin{array}{l}\text { activity cost } \\
\text {-documen- }\end{array}$ & $\begin{array}{l}\text { units } \\
\text { of activity } \\
\text { measure }\end{array}$ & $\begin{array}{l}\text { size of a production } \\
\text { batch }\end{array}$ \\
\hline & paring & $\begin{array}{l}\text { rate of ac- } \\
\text { tivity }\end{array}$ & $\begin{array}{l}\text { type of documenta- } \\
\text { tion (typical, modified, } \\
\text { new) }\end{array}$ \\
\hline & $\ldots$ & ... & ... \\
\hline
\end{tabular}

COST ESTIMATION DEPENDING ON THE AVAILABLE INFORMATION ON THE NEW ELEMENT AND THE CLOSEST ELEMENT IN THE DATABASE

The costs estimated when using the proposed method are costs characterized by a various level of accuracy in relations to actual costs of the designed element. The costs are established on the basis of cost drivers values, which are selected according to different algorithms, depending on level of information on the new item and its closest counterpart in the database. The more information is available, the better is the adjustment of the values of cost drivers to actual values related to the designed element. Depending on the amount of the information on the designed item, the following costs are estimated:

- Variant cost of the designed element (Fig. 5), which is determined on the basis of the manufacturing process of the closest element and the data related to the values of cost drivers in connection with a cost calculation system. The next step is to search the exiting CAPP system's base of the manufacturing processes from the perspective of feature similarity, in order to find a technological process route for a previously designed element, and particularly a set of data connected to technological processes in different variants, the semi-product - its shape, dimensions, type of materials, machining time standards, tools, production means, production workstations organization, etc. Each element of this set has some ascribed values which are characteristic for the parameters of processing the model element. On the basis of these values and a set of cost drivers of the variant model of cost estimation, a variant set of cost drivers' values is determined, which, taking into account current rates of activity costs, allows for evaluating variant cost of the designed element, according to cost data from a current, not historical, time period.

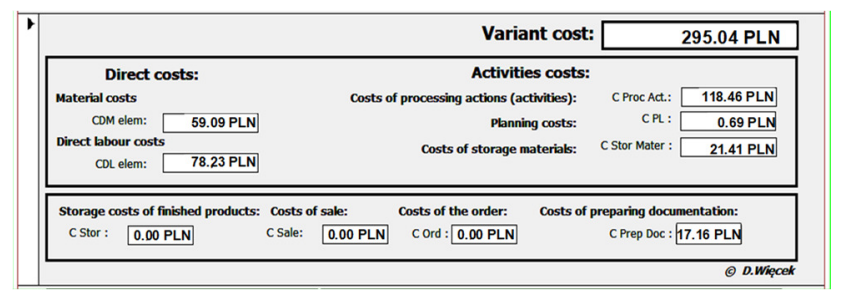

Fig. 5 Estimated variant costs of the designed element

- Corrected variant cost, which is a cost determined on the basis of corrected values of cost drivers basing on parameter differences of the designed element and its closest counterpart-Figure 6. The parametric description and the determined variant costs of the designed element will be used by correcting the so called cost drivers according to activity based costing respectively to the existing differences between the elements. The cost drivers to be corrected can be related to e.g.:

- cost of direct materials, as a result of applying another kind of raw material, semi-product, or differences in size; 
cost of direct labor and costs of processing activities (Fig. 7), resulting from changing time consumption standard following altered machinability parameters, size of a production batch, etc.

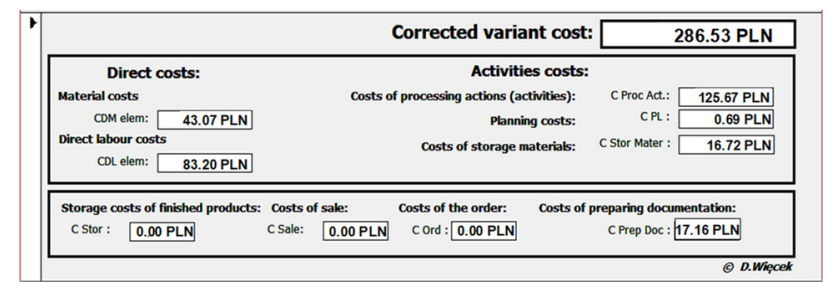

Fig. 6 Estimated corrected variant costs of the designed element

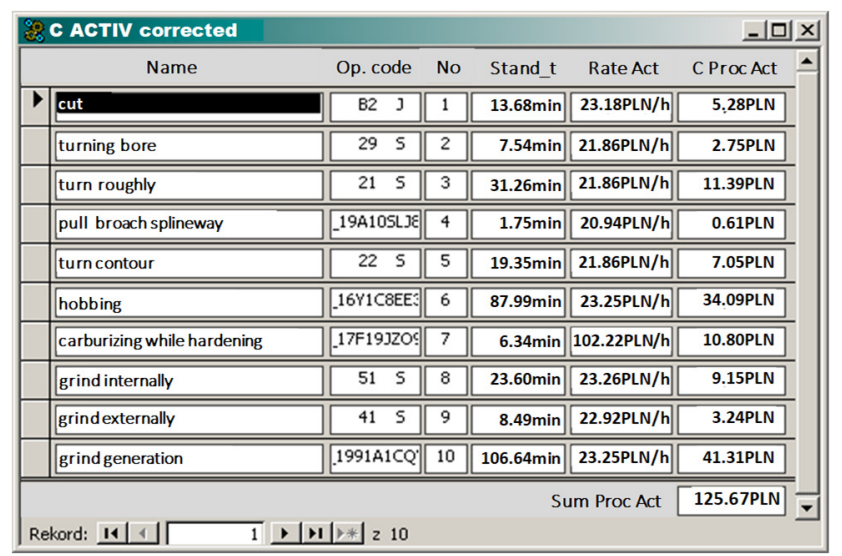

Fig. 7 Corrected variant costs of processing activities

- Generative cost, which is a cost determined on the basis of generative sets of cost drivers values for the designed element. It is necessary that all features describing the designed element are clearly defined - they are partly selected from CAD and CAPP databases. Achieving the assumed constructional form in specific organizational and technical conditions requires performing a set of activities resulting from the appearance of given features in the description of the designed element, i.e. planning specific technological operations, in order to obtain the desired parameters of a given feature. The technological process framework is adopted using an advisory system which, based on specific features of the designed element, proposes a given variant of the technological process with the working time standard for a given operation. The production costs for an element do not only depend on the set of activities present during processing, but also on cost drivers dependent on materials or organizational characteristics, like the cost of direct materials or costs of production planning activities. Analyzing the set of cost drivers related to the generative model of costing for machine elements, taking into consideration the level of cost aggregation, it appears that the process of generating a set of cost drivers values concerns: direct costs of materials (raw materials, semi-products, dimensions), costs of direct labor and processing activities (technological operations, the manufacturing process variant, attribution to production workstations), other costs of activities (storing, planning, etc.). Cost estimation proceeds with a much higher accuracy than cost correction for the previously designed elements (the variant method, the corrected method).

- Hybrid cost - this approach finds application when a set of characteristics describing the designed element has not been fully determined. In such an event, it is not possible to use only generative approach to creating cost drivers, since the established estimated costs on an incomplete set would significantly differ from actual costs. The hybrid approach applies the rules of selecting a variant set of cost drivers and creating a generative set of cost driver values. The basis for determining this cost is the value of corrected variant cost decreased by the value of generative costs set for the variant element, and increased by the value of generative costs specified for the designed element, i.e. the costs of technological operations and direct materials - Figure 8.

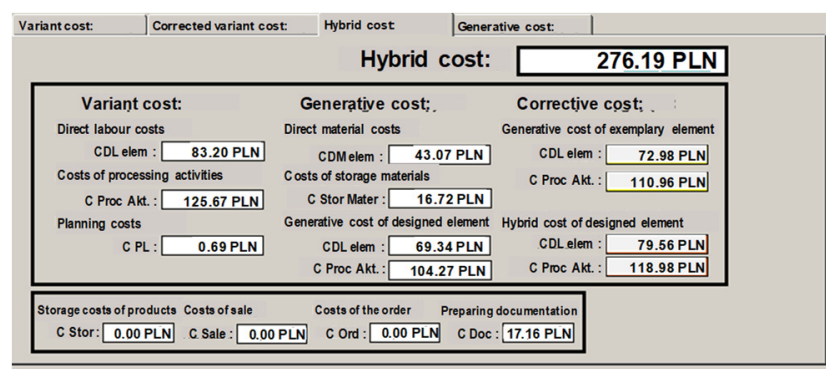

Fig. 8 The estimated hybrid cost of the designed element

The available set of data on the designed element rarely provides the basis for generating a full set of sub-activities of the manufacturing process. Therefore, it is necessary to combine a set of values of cost drivers generated by the variant and generative methods in order to avoid the dependency of cost estimation on similarity with the nearest element in case of the variant method, and information shortage in case of the generative method. Such an approach to generating the values of cost drivers is called the hybrid approach.

\section{CONCLUSIONS}

The parameter values of constructional, manufacturing and organizational features of machine elements determined on the stage of production processes design directly influence and shape the values of prime costs related to subsequent production processes. Estimation accuracy depends on the available information on the designed element and requires creating proper models of determining costs basing on activity based costing, which would allow for more precise determination of resources consumption for a given cost object on each stage of production processes design. Particular cost components rely on the variables called cost drivers, therefore, we can state that the value of a given cost component is a function of a certain set of cost drivers related to a given cost component. The suggested method bases on the required sets of cost drivers, which allows to estimate costs possibly most similar to actual costs by applying current rates in a given time period (activity costs in previous periods are not considered). 
Getting to know the value of activity costs allows to reduce production costs by means of decisions to eliminate or limit the duration and to reduce the use of resources of the activities that do not add value to products. Designers and cost managers have the opportunity of paying attention to low-cost activities and choosing less expensive activities, in particular cheaper "construction components" in the product design phase.

The proposed methods require full implementation of activity based costing in an enterprise, a functioning CAPP system with an updated base of technological possibilities of the manufacturing system and conducting an analysis of constructional documentation in order to create a base of features describing the designed elements. The suggested solutions have been adjusted to production systems operating in conditions of unit and small lot production.

\section{REFERENCES}

[1] K. Dohn, A. Gumiński and A. Pawluś. "Supply processes in a machine-building enterprise concerning metallurgical products - case study", in Proc. of 24th International Conference on Metallurgy and Materials, 2015, pp. 1902-1907.

[2] I. Kuric. "New methods and trends in product development and planning", in Proc. of 1st Inter-national Conference on Quality and Innovation in Engineering and Management, 2011, pp. 453-456.

[3] D. Plinta and M. Krajcovic. "Production system designing with the use of digital factory and augmented reality technologies", in Proc. of International Conference on Automation ICA 2015, Advances in Intelligent Systems and Computing, vol. 350, 2015, pp. 187-196.

[4] T. Farineau, B. Rabenasolo, J.M. Castelain, Y. Meyer and P. Duverlie. "Use of Parametric Models in an Economic Evaluation Step During the Design Phase". International Journal of Advanced Manufacturing Technology, vol. 17, no. 2, pp. 79-86, 2001.

[5] A. Saniuk, S. Saniuk and K. Witkowski. "Using activity based costing in the metalworking processes", in

\footnotetext{
Dorota Więcek, PhD, Dariusz Więcek PhD

University of Bielsko-Biala,

Faculty of Mechanical Engineering

and Computer Science

ul. Willowa 2, 43-309 Bielsko-Biala, Poland

e-mail:dwiecek@ath.bielsko.pl

wiecekd@ath.bielsko.pl
}

\section{Prof. Ivan Kuric}

University of Zilina,

Faculty of Mechanical Engineering,

Univerzitna 8215/1, 01026 Zilina, Slovak Republic

e-mail: ivan.kuric@fstroj.uniza.sk
Proc. of $19^{\text {th }}$ International Metallurgical and Materials Conference METAL 2010, 2011, pp. 1328-1333.

[6] L. Qian and D. Ben-Arieh. "Parametric cost estimation based on activity-based costing: A case study for design and development of rotational parts". International Journal of Production Economics, vol. 113, no. 2, pp. 805-818, 2008.

[7] N. Sajadfar and Y. Ma. "A hybrid cost estimation framework based on feature-oriented data mining approach". Advanced Engineering Informatics, vol. 29, no. 3, pp. 633-647, 2015.

[8] Ch. Hueber, K. Horejsi and R. Schledjewski. "Review of cost estimation: methods and models for aerospace composite manufacturing". Advanced Manufacturing: Polymer \& Composites Science, vol. 2, no. 1, pp. 1-13, 2016.

[9] D. Więcek and D. Więcek. "Production Costs of Machine Elements Estimated in the Design Phase", in Intelligent Systems in Production Engineering and Maintenance - ISPEM 2017. Advances in Intelligent Systems and Computing, vol. 637, A. Burduk and D. Mazurkiewicz, Eds. Cham: Springer, 2018, pp. 380391.

[10] J. Mleczko and L. Dulina. "Manufacturing documentation for the high-variety products". Management and Production Engineering Review, vol. 5, no. 3, pp. 53-61, 2014.

[11] D. Więcek. "Implementation of artificial intelligence in estimating prime costs of producing machine elements". Advances in Manufacturing Science and Technology, vol. 37, no. 1, pp. 43-53, 2013.

[12] J. Matuszek and A. Moczała. "The modelling and simulation method in computer aided co-operation". Control and Cybernetics, vol. 39, pp. 117-131, 2010.

[13] M. Relich, A. Świć and A. Gola. "A knowledge-based approach to product concept screening", in Proc. of 12th International Conference Advances in Intelligent Systems and Computing, vol. 373, 2015, pp. 341-348. 